\title{
The Utilization of Social Media by Collegiate Aviation Faculty
}

\author{
C. Daniel Prather \\ Middle Tennessee State University
}

\begin{abstract}
Social media has taken the world by storm, and there seems to be no slowing down. Young or old, social media has infiltrated our lives in a way never before imagined. Although there are pros and cons to the many social media platforms currently available, it is beneficial for collegiate aviation faculty to learn more about these various tools to determine how, if at all, they can benefit our students. As such, this paper conducted a study of collegiate aviation faculty nationwide and determined that collegiate aviation faculty are very aware of the five most popular social media sites (Skype, YouTube, Facebook, Wikipedia, and Twitter), regularly use YouTube and Wikipedia as part of academic courses, and feel that social photo and video sharing sites provide the most benefit to students. The paper also presents ideas in how to adopt three lesser used social media sites (Twitter, LinkedIn, and Ning) for the benefit of students.
\end{abstract}

\section{INTRODUCTION}

Millennials thrive in an always 'on' world filled with digital music devices, cell phones, the Internet, instant messenger and social networks. They are in constant touch, updating their friends with texts (80 per day on average according to Nielsen), tweets and messages on the 'walls' of their Facebook profiles. This world of interactivity and hypercommunication has fundamentally changed how teenagers and young adults receive, process and act on information (Barnes \& Mattson, 2010).

Social media was relied upon by 774 million people worldwide in 2010 - including children, teens, and adults. Having grown from 373 million users in 2007, it is expected to grow to over 1 billion users by 2012 , which equates to $21 \%$ of the worldwide population. With so many users, social media is changing the way we interact and "socialize" with the world around us. Aspiring brides- and grooms-tobe are finding their love, marrying, and beginning a family. Long-lost family members are being reunited. Law enforcement personnel are capturing criminals. At the same time, however, students are being bullied. Spouses are having affairs. Employee productivity is being lost. While there is nothing new about these events, they have been aided, whether positively or negatively, by the use of social media (Olausson, 2007).

With both pros and cons to social media, one wonders about the impacts of such media on higher education. Clearly, the use of social media within higher education is changing the landscape of how students interact, how students learn, and how faculty interact with students. Consider a walk through the hallway prior to class. Many of the students standing in the hallway are interacting with each other, but not in person; rather, they are using social media to communicate, possibly even with the peer standing next to them. It seems many of them are plugged in, but out of touch at the same time. Possibly the same could be said of faculty. Indeed, it has been said that undivided attention may be the most valued commodity of the $21^{\text {st }}$ century.

With today's traditional college student having been born between 1989 and 1993, we as faculty are educating a generation of students that grew up with computers and the ability to communicate electronically. As educators, we should be aware of the abilities of such technology and decide for ourselves how to best utilize this technology. Specifically regarding social media, faculty currently use 
this type of technology personally, as well as professionally. This article examines the use of social media by faculty within collegiate aviation.

\section{REVIEW OF LITERATURE}

Social media, by its very nature, is difficult to define. For the first time, we as humans are face-toface with a digital medium that is "user-created, user-controlled, flexible, democratic, and both very transparent and very not so" (Moran, Seaman, \& Tinti-Kane, 2011, p. 4). Perhaps the most unique aspect of social media is that once content is shared, it invites conversation. As a result, social media is dynamic, interactive, and inviting. Suffice to say, social media comprises "activities that involve socializing and networking online through words, pictures, and videos” (Ruben, 2008, p. 1).

Although Facebook is the most popular social network with more than 500 million active users, it belongs to only one of ten categories of social media ("Facebook Statistics," 2011; Reuben, 2008). According to Cavazza (2008), there are ten categories of the social media landscape (graphically shown in Figure 1):

1. Publication tools
a. Blogs
b. Wikis
c. Citizen journalism portals

2. Sharing tools
a. Videos
b. Pictures
c. Links
d. Music
e. Slideshows
f. Product reviews
g. Product feedback

3. Discussion tools
a. Forums
b. Video forums
c. Instant messaging
d. VoIP

4. Social networks
a. General social networks
b. Niche social networks
c. Tools for creating social networks

5. Micropublication tools

6. Social aggregation tools

7. Livecast hosting platforms

8. Virtual worlds

9. Social gaming platforms

10. Massively multiplayer online games (MMO) or massively multiplayer online role playing games (MMORPG) 


\section{Social Media Landscape}

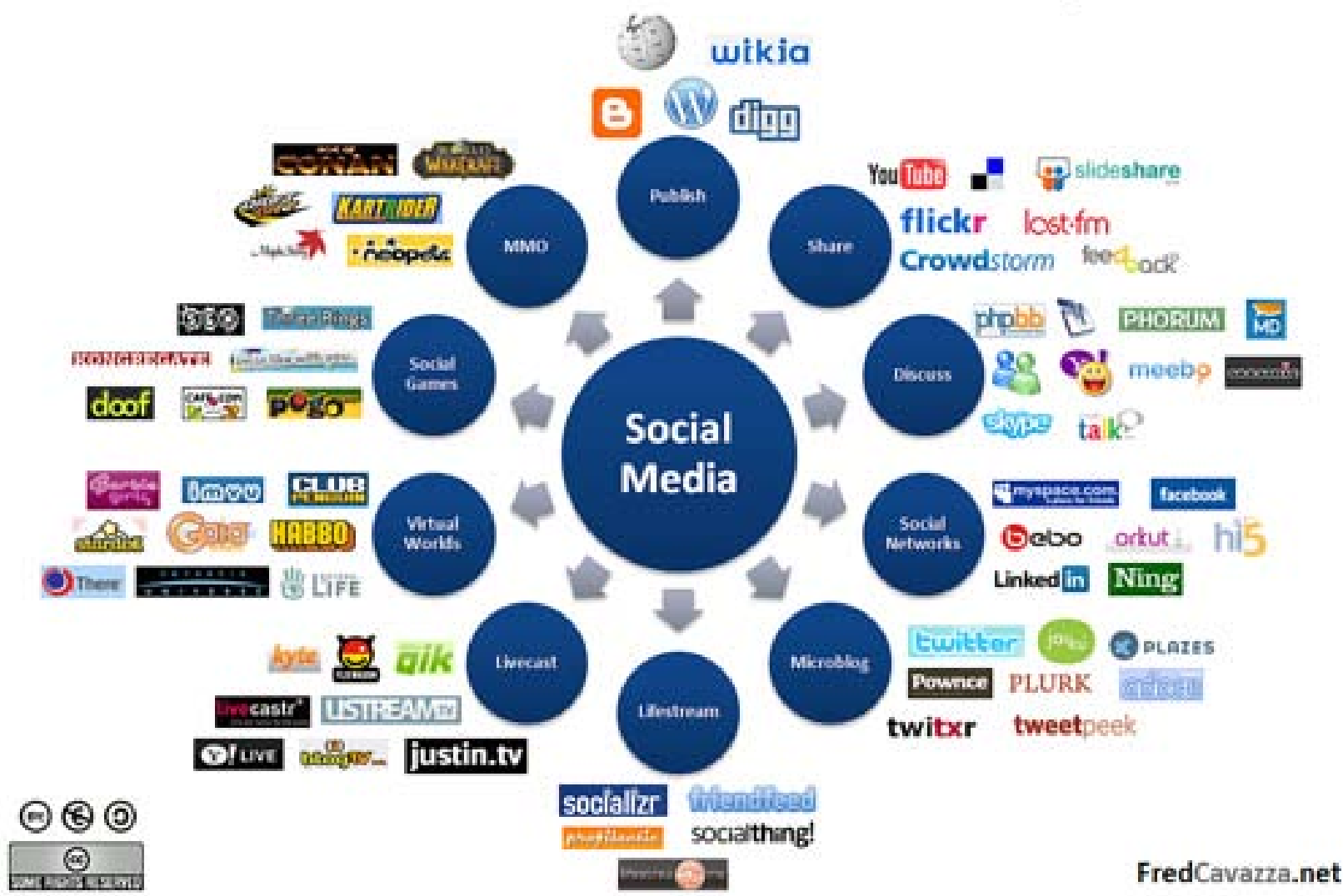

Figure 1. Social Media Landscape

Source: Cavazza, 2008.

Although this landscape can be quite intimidating, especially for faculty that may not even use social media in their personal lives, five of these ten categories contain the social media sites most commonly used by faculty both personally and professionally, according to a 2011 study conducted by Pearson (Moran, et. al, 2011). These categories, with the most popular sites among faculty in parenthesis, are as follows:

1. Publication tools (Wikipedia)

2. Sharing tools (YouTube, Flickr)

3. Discussion tools (Skype)

4. Social networks (Facebook)

5. Micropublication tools (Twitter)

Even among similar categories, the characteristics of these sites vary. The characteristics of the most popular social media sites, as well as their use by faculty nationwide, are presented below. 


\section{Wikipedia}

A wiki is a website that allows the creation and editing of interlinked web pages without knowledge of HTML. Wikipedia is a wiki that is a web-based, collaborative, multilingual encyclopedia. It boasts 18 million articles (with over 3.6 million in English) that have been written collaboratively by volunteers from around the world ("Wikipedia," 2011). Characteristic of Wikis, Wikipedia entries can generally be edited by anyone with access to the site. This is, of course, the main reason why faculty are hesitant to use Wikipedia or allow students to use it as a reference for research projects. Even so, according to Moran et. al. (2011), 5\% of surveyed faculty post on Wikis (of a personal nature) while 14\% visit (of a personal nature) in a given month. Of these faculty, 28\% use Wikis for professional (nonclass) purposes. Although the study only examined Wikis, and not Wikipedia specifically, it discovered that $9 \%$ of faculty use Wikis in class and 6\% use Wikis to post content for class. At the same time, $11 \%$ of faculty assign students to read/view Wiki posts, while 7\% assign students to post on a Wiki.

\section{YouTube}

YouTube is considered the world leader in online video, and has become the number one source to watch and share original videos. The interface allows users the opportunity to easily upload and share video clips, which can be accessed through websites, mobile devices, blogs, and email (Reuben, 2008). YouTube boasts that more than 13 million hours of video were uploaded during 2010 and 35 hours of video are uploaded every minute. In fact, more video is uploaded to YouTube in 60 days than the 3 major U.S. networks created in 60 years ("Youtube statistics," 2011). According to Moran et. al. (2011), only $8 \%$ of surveyed faculty post on YouTube (of a personal nature) while $49 \%$ visit (of a personal nature) in a given month. Of these faculty, $57 \%$ use this site for professional (nonclass) purposes. Although the study did not specify YouTube, $61 \%$ of surveyed faculty access online video in class and $21 \%$ post online video for class. Likewise, $32 \%$ of faculty assign students to view online video, while $10 \%$ assign students to post online video.

\section{Flickr}

Flickr is an online photo sharing site that allows users to upload photos that can be organized in sets and collections. Photos can then be viewed and commented on by others (Reuben, 2008). Flickr is currently home to over five billion digital images ("Flickr explore," 2011). According to Moran et. al. (2011), only $2 \%$ of surveyed faculty post on Flickr (of a personal nature) and 6\% visit (of a personal nature) in a given month. Of these faculty, $11 \%$ use this site for professional (nonclass) purposes. The Pearson study did not investigate the use of Flickr or similar photo sharing sites with regards to class use, yet it is clear that Flick is not that popular among faculty.

\section{Skype}

Skype allows users to communicate with each other via text, voice, and video on a telephone, computer, or TV with Skype software. It also allows group video and conference calling. Skype has an average of 145 million connected users monthly. Skype users made 207 billion minutes of voice and video calls in 2010, approximately 42\% of which was video (“About skype,” 2011). Unfortunately, the Pearson study did not analyze the use of discussion tools, such as Skype.

\section{Facebook}

Facebook, with more than 500 million active users and over 900 million objects to interact with, is the most popular social network and likely the most popular social media ("Facebook Statistics," 2011). This social utility connects people by allowing the sharing of photos, links, videos, content, and more. 
Although it was originally launched for Harvard University students in 2004, the site now welcomes anyone over the age of 13 . Facebook is made up of six components: personal profiles, status updates, networks, groups, applications, and fan pages (Reuben, 2008). According to Moran et. al. (2011), 43\% of surveyed faculty post on Facebook (of a personal nature) and 57\% visit (of a personal nature) in a given month. Of these faculty, $45 \%$ use this network for professional (nonclass) purposes. However, only $4 \%$ use Facebook in class, only 3\% use it to post content for class, and only $3 \%$ and $2 \%$, respectively, assign students to $\mathrm{read} / \mathrm{view}$ or post.

\section{Twitter}

Twitter is categorized as a micropublication tool because users are limited to 140-character updates. The site is considered a cross between instant messaging and blogging. Users can also follow the updates ("tweets") posted by people they follow, send them direct messages, reply publicly to friends, or post questions or comments as their status update (Reuben, 2008). The top users of this site have almost 11 million followers ("Twitter users you should follow," 2011). According to Moran et. al. (2011), only 6\% of surveyed faculty post on Twitter (of a personal nature) and 11\% visit (of a personal nature) in a given month. Of these faculty, 13\% use this network for professional (nonclass) purposes. Only 2\% use Twitter in class, to post content for class, or assign students to read/view posts. Clearly, Twitter is not widely used among faculty.

\section{RESEARCH METHOD}

To gather faculty perceptions regarding social media and determine the manner in which social media is being utilized by collegiate aviation faculty, the researcher identified the nationwide population of collegiate aviation faculty for this study. The most complete contact information for this population is maintained by the University Aviation Association (UAA). As a result, the researcher utilized the entire professional membership listing for the UAA, which included 199 members at the time of the study.

To gather data from collegiate aviation faculty, a brief, online questionnaire was developed. The unique researcher-designed questionnaire for this project contained 11 items, and focused on the personal and professional use of social media by collegiate aviation faculty, the perceived use of social media among collegiate aviation students, and the specific integration of social media within academic courses by collegiate aviation faculty. During late Spring 2011, IRB approval for this project was granted. During early summer 2011, the survey of collegiate aviation faculty was conducted. After an initial contact and one follow-up, the study yielded 80 responses, equating to a $40.2 \%$ response rate.

Responses represent a wide range of collegiate aviation programs. For instance, $94.7 \%$ of participants represent four-year institutions, while 5.3\% represent two-year institutions. Programs of all sizes, based on the number of students, were also represented. The most common size programs are: 90 119 students (13\% of participants), 190-229 students (11.7\%), and 600 or more students (22.1\%). Lastly, programs with less than 3 faculty to 19 or more were represented. The three most common size programs, based on the number of collegiate aviation faculty, are: 3-6 faculty (26\% of participants), $7-10$ faculty (18.2\%), and 19 or more faculty (28.6\%).

The following questions guided this research effort:

1. What social media platforms are most popular and how do they work?

2. In what way do collegiate aviation faculty currently utilize social media in the classroom?

3. How can collegiate aviation faculty use social media to reach and interact with students? 
It should be noted that this study only examined faculty perceptions and did not gather data from students or the general population. As such, these results only reflect perceptions of collegiate aviation faculty in the U.S.

\section{RESULTS}

To gain insight into the popularity of social media by collegiate aviation students, faculty participating in this study were asked to define the percentage of their students utilizing social media on a regular basis (defined as five or more days per week). Although students were not surveyed, and this finding only indicates faculty perception, no less than $72 \%$ of participants indicate that over $80 \%$ of their students interact with social media regularly.

Collegiate aviation faculty were also asked about their use of social media. A large majority, 80\%, utilize some form of social media in their personal life. However, professionally, only $49 \%$ use social media.

Participants were also queried about their degree of awareness of the various social media tools. As seen in Figure 2, participants were most aware of the six most popular social media sites discussed previously. Specifically, Skype, YouTube, Facebook, Wikipedia, and Twitter were all very familiar to the participants. These findings among collegiate aviation faculty were similar to findings among faculty nationwide (as presented in the Pearson study), with the exception of Flickr. Among faculty nationwide, 84\% were aware of Flickr, whereas 59.8\% of collegiate aviation faculty are (Moran, et. al., 2011).

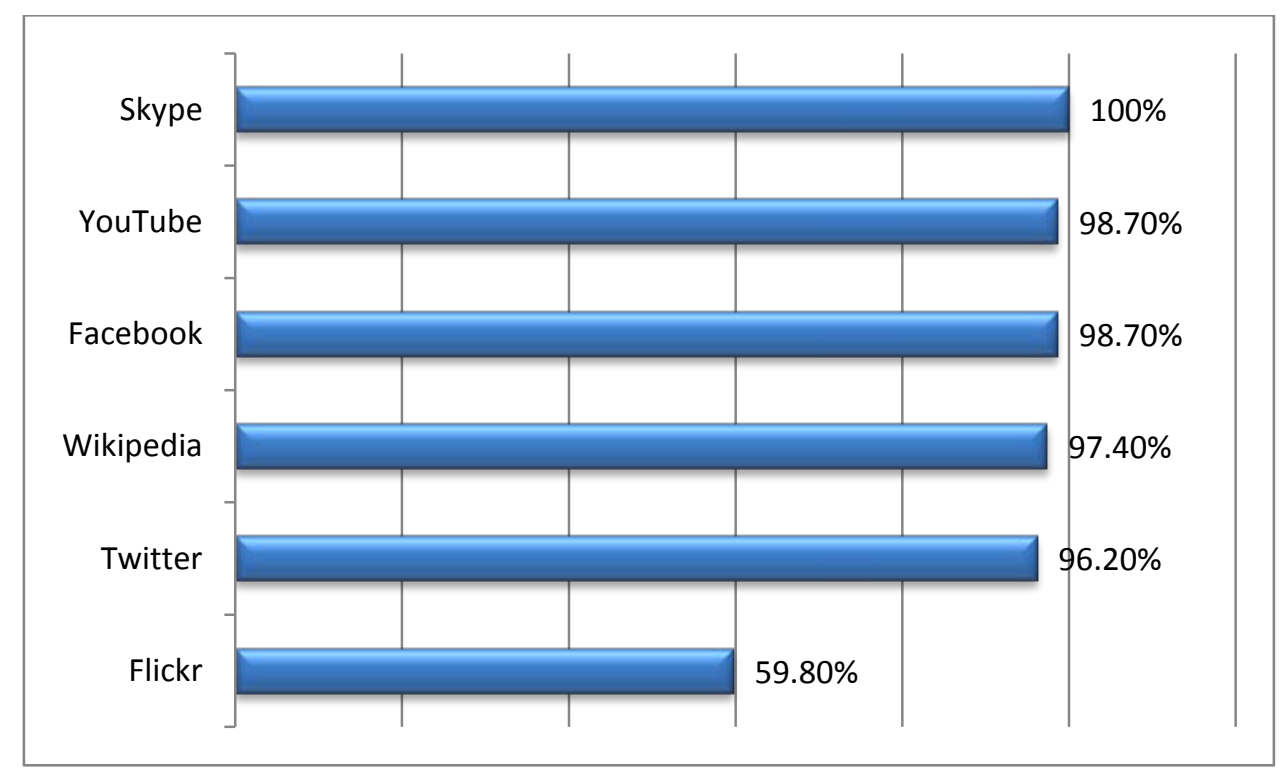

Figure 2. Degree of Awareness

(Note: Percentages represent total responses in the categories of "very aware” and "somewhat aware.”)

When presented with the various social media tools and asked to designate how frequently these tools are used as part of academic courses, collegiate aviation faculty once again chose the six most popular sites previously discussed (Figure 3). It appears that YouTube is used most frequently on a daily or monthly basis, while Wikipedia is used second most frequently. The popularity of YouTube among collegiate aviation faculty is comparable to faculty nationwide (according to Moran, et. al., 2011). 
However, it appears that collegiate aviation faculty utilize Wikipedia as part of an academic course more so than do faculty nationwide (50\% compared to only 6-11\%, respectively).

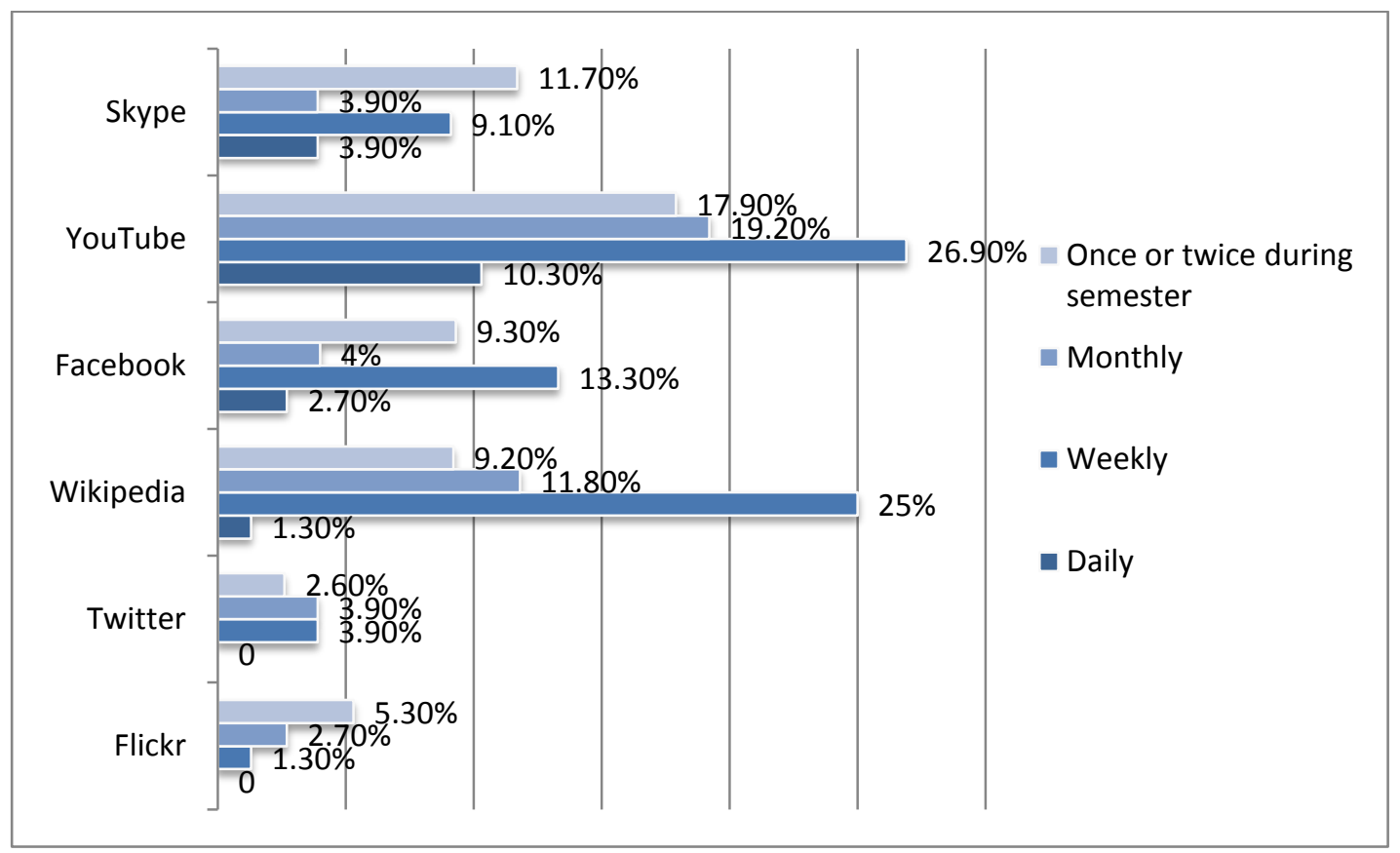

Figure 3. Frequency of use of social media in academic courses

When asked how beneficial the various categories of social media tools can be to collegiate aviation students if properly utilized by faculty, the findings were similar to findings of faculty nationwide, although collegiate aviation faculty are slightly less enthusiastic about the benefits. It is clear, however, that collegiate aviation faculty do perceive some benefits of these various tools.

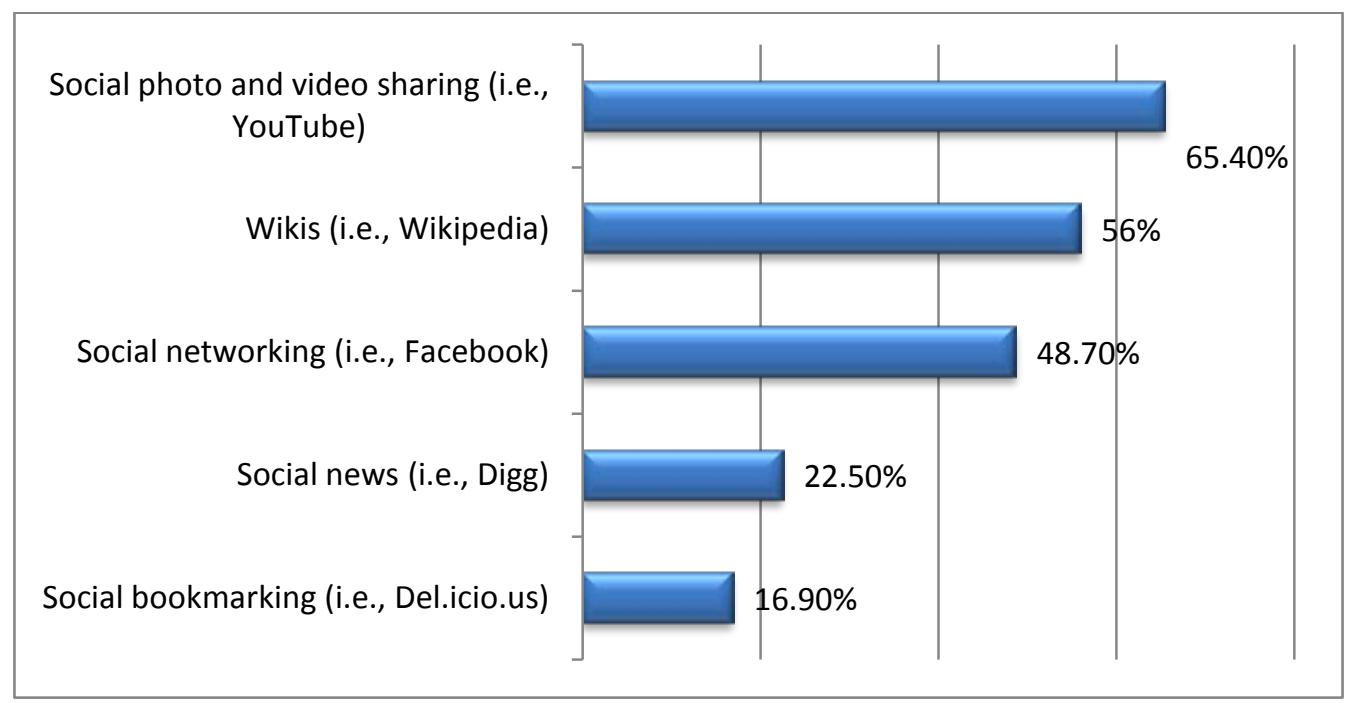

Figure 4. Degree of social media benefits

(Note: Percentages represent total responses in the categories of "Very beneficial” and "beneficial.”) 
To determine in what way these social media tools are currently being utilized as part of academic courses, collegiate aviation faculty were asked to share in that regard. Although the responses to this open-ended item varied, some common themes emerged.

First, it is quite clear from the responses that YouTube is most heavily utilized in the classroom. The reasons for this include: videos of aircraft accidents, accident investigations, and human factor issues; stimulating humor; integrating a visual component to the class; explaining a concept better; stimulating discussions; and gaining student attention.

It appears from the responses that Wikipedia is the second most popular social platform in the classroom. It is used for initial fact finding, general information, presenting concepts in layman's terms, beginning research, quickly looking up a term or concept, exploring links in the reference section, and finding various graphs for use in PowerPoint slides. However, faculty should be cautioned that as a Wiki, Wikipedia suffers from a lack of verified accuracy, resulting in questionable credibility.

Skype appears to be the third-most used social media tool as part of academic courses. It is used for guest speakers, one-on-one conferencing, communication with students at satellite campuses, communication between students and faculty while the faculty is away from campus, and interaction between students in a lab.

It appears that Facebook and Twitter are also used as part of academic courses, but to a much lesser degree than YouTube, Wikipedia, and Skype. Generally Facebook is used to stay connected to and interact with students. Twitter is used by at least one faculty member to post class and location status updates for his/her class.

\section{DISCUSSION}

According to Blankenship (2011), social media is becoming "so dominant in the classroom that it's hard to imagine any professor or student making it through a week without them (p. 39)." However, as the Pearson study showed, social media tools can be used by faculty in class, for postings outside of class, and/or as part of student assignments. Likewise, faculty can use social media personally and for professional nonclass use. According to the results of this study, it appears that collegiate aviation faculty use YouTube regularly to show videos in class, but don't necessarily post videos on this site. Facebook is used quite heavily by faculty, but likely to keep in touch with old college friends, rather than in the classroom. Skype is used occasionally in the classroom, while Wikis and Flickr are not used very often.

It is clear, however, that social media is being utilized by a large percentage of collegiate aviation faculty, as well as faculty nationwide. As Rheingold (as cited in Blankenship, 2011) states, the benefits of social media to students are plenty, including "greater engagement, greater interest, [and] students taking more control and responsibility for their education” (p. 40). Although some may question these benefits, clearly, "It's a lot more work for a professor to use social media properly, to comment on a blog, or edit a wiki” (p. 41). And, as Rheingold asks, "Are the professors getting paid more for that? Probably not” (p. 41).

Even so, there are effective ways to utilize social media in class, outside of class, and as part of student assignments. To provide ideas for and stimulate discussion on the use of social media, as well as introduce three social media platforms that are not as popular among collegiate aviation faculty, three unique examples are presented below. 


\section{Twitter}

Even though Twitter only allows concise 140-character "tweets," students can benefit from this site in several ways. In the classroom, faculty can use Twitter to follow various members, such as Ray LaHood, the U.S. Secretary of Transportation (@RayLaHood) or the International Civil Aviation Organization (@ICAOHQ). Their "tweets" will likely stimulate discussion and allow faculty to bring current events into the classroom. Outside of class, faculty can use Twitter to immediately "tweet" news, course information, class cancellations, and more to students. Regarding student assignments, students can be assigned members to follow on Twitter or even learn to leverage Twitter in developing a personal brand. Although LinkedIn is probably the best place to begin building a personal brand, Twitter allows a student to leverage the growth of that brand by producing a particular "voice" and engaging in micropublication. Students will also benefit from the 140-character limit of Twitter. Presenting their ideas in a concise fashion takes work, but leads to more in-depth thought as students try to avoid going over the Twitterimposed character limit (“About Twitter,” 2011).

\section{LinkedIn}

Although LinkedIn is considered a professional social network, faculty can effectively leverage this site to benefit students. In the classroom, faculty can post questions to industry experts and obtain quick answers. Faculty can also search through position announcements to benefit students. Outside of class, faculty can post various updates to their profile and respond to student questions. As an assignment, students (particularly senior-level students) could be required to develop a professional profile on this site. By encouraging students to begin thinking in "real-world" terms and requiring them to build an online, Linked-in style resume, students will understand the importance of developing a professional image. As an added bonus, there have been many instances of employers scanning profiles on LinkedIn and finding potential employees (“About us,” 2011).

\section{Ning}

Social networks are amazingly popular today. Even so, some faculty feel they have limited use in the classroom, or even outside for that matter. Outside the classroom, faculty should be cautious of becoming friends with students in a social network. This is especially true because the faculty member has no control over that social network (other than the content they post). However, students love social networks and faculty can benefit from the ability to stay connected to, and communicate with, students outside of class.

Although almost 95\% of survey respondents are unaware of Ning, it is one solution to this social network dilemma. Ning is a social media platform that almost $95 \%$ of collegiate aviation faculty are unaware of, according to the results of this study. As a social network, it does not necessarily compete with Facebook and MySpace. Rather, Ning allows for a unique social network to be built by the Administrator, allowing only invited members to participate. The Administrator maintains complete control over users, content, etc. Once up and running, students are invited to join, and can build their profile. They can post photos, share videos, make friends, post messages on a wall, send private messages, and develop blog posts and forums. The Administrator has complete control over the entire social network, including the degree of control given to users (students). The one drawback is the cost. However, it is quite reasonable. Depending on the pricing plan selected, the annual cost varies from \$19.95 to \$239.90 to \$599.90 (“About ning,” 2011).

In the classroom, faculty can bring up the Ning network and showcase photos, videos, and blogs posted by students. Outside of class, students can communicate with each other in groups, and learn about job opportunities and other newsworthy events posted by faculty or other members. Students can 
be assigned to various groups and be required to communicate outside of class using this platform. They can also be assigned a blog and be required to regularly update it.

As a faculty member at Middle Tennessee State University, I have developed a very effective social network for students in the Aerospace Administration (Aviation Management) concentration. This network allows me to post job announcements, internship opportunities, departmental news and events, photos, video, blog posts, and much more. Students are very appreciative and thoroughly enjoy the site. If this is being considered, however, it is imperative to develop User Guidelines, as below:

This site has been created by Dr. Prather to allow MTSU Aerospace Administration students to stay connected. Here, you can share all of your wonderful aviation adventures, network with classmates, and keep up on the latest events and opportunities in Aviation. Since aviation is an extremely professional industry, we ask that any posted pictures, blogs, comments, etc. be directly related to aviation. Although this is a social network, it is not Facebook, and is considered an extension of the classroom. Therefore, if you wouldn't do it in class, please don't do it on here. We reserve the right to promptly remove any members violating this policy. Thanks and enjoy!

With these guidelines in place, I have only had to ask two members to remove a photograph, and if desired, the Administrator can approve all photos before they are even posted. In that way, a social network can be developed whereby a faculty member is in complete control.

\section{CONCLUSION}

"I do not think we understand ... how the web is going to reshape what we do. (Bollinger, as cited in Miller, 2011, para. 7). The web is definitely changing how we gather information and interact with the world around us. Based on their rapid growth and rise in popularity (among all demographics), it would seem that social media tools are here to stay. According to Moran et. al. (2011), "Higher education's ability to take advantage of social media for promoting professional development, broadening institutional research, and increasing student success is nothing short of revolutionary" (p. 4). Regardless of whether collegiate aviation faculty agree with this statement, research suggests that we "start empowering ourselves to use social media well” (Blankenship, 2011, p. 42). For some of us, that might mean not using social media at all, or at least not in the classroom. For others, it might mean integrating social media into every class session. Wherever each of us find ourselves along that continuum, our choices should be well-informed, which was a goal of this study. 


\section{REFERENCES}

About ning. (2011). Retrieved from http://about.ning.com/

About skype. (2011). Retrieved from http://about.skype.com/

About twitter. (2011). Retrieved from http://twitter.com/about

About us. (2011). Retrieved from http://press.linkedin.com/about

Barnes, N. G. and Mattson, E. (2010). Social media and college admissions: Higher-ed beats business in adoption of new tools for third year. Retrieved from http://www.umassd.edu/cmr/studiesandresearch/socialmediaandcollegeadmissions2010study/

Blankenship, M. (2011). How social media can and should impact higher education. Education Digest, 76(7), 39-42.

Cavazza, F. (2008). Social media landscape. Retrieved from http://www.fredcavazza.net/2008/06/09/social-media-landscape/

Facebook Statistics. (2011). Retrieved from http://www.facebook.com/press/info.php?statistics

Flickr explore. (2011). Retrieved from http://www.flickr.com/

Miller, E. D. (2011). Rethinking higher education in an online and recession-wary world. National Teaching and Learning Forum Newsletter, 20(3).

Moran, M., Seaman, J., and Tinti-Kane, H. (2011). Teaching, learning, and sharing: How today's higher education faculty use social media. Pearson: Boston. Retrieved from http://www.pearsonlearningsolutions.com/educators/pearson-social-media-survey-2011-bw.pdf

Olausson, M. (2007). The People’s Revolution: Implications of Web 2.0 and Social Media Applications. Retrieved from http://www.strategyanalytics.com/default.aspx?mod=reportabstractviewer\&a0=3690

Reuben, R. (2008). The use of social media in higher education for marketing and communications: A guide for professionals in higher education. Retrieved from http://doteduguru.com/id423-socialmedia-uses-higher-education-marketing-communication.html

Twitter users you should follow. (2011). Retrieved from http://twitaholic.com/

YouTube Statistics. (2011). Retrieved from http://www.youtube.com/t/press_statistics

Wikipedia. (2011). Retrieved from http://en.wikipedia.org/wiki/Wikipedia 